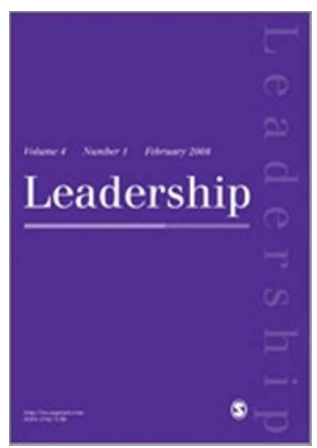

\title{
Leadership talk: from managerialism to leaderism in healthcare after the crash
}

\begin{tabular}{|r|l|}
\hline Journal: & Leadership \\
\hline Manuscript ID: & LEA-14-0062.R1 \\
\hline Manuscript Type: & Special Issue: Leadership and Authority in a Crises-constructing World \\
\hline Keywords: & leadership, leaderism, management, healthcare, NHS \\
\hline Abstract: & $\begin{array}{l}\text { The economic downturn that began in 2008 led to massive cuts in spending } \\
\text { targeted at managerial activities in the UK National Health Service (NHS). } \\
\text { The appellation 'manager' once conferred status in the NHS (Learmonth, } \\
\text { 2005). However, managers have borne the brunt of reform and the term } \\
\text { itself is in danger of falling into disrepute. Drawing upon perspectives on } \\
\text { leadership that emphasise its constitutive nature (Grint, 1997, 2005), we } \\
\text { examine the growing alternative emergent culture of 'leaderism' in the NHS } \\
\text { (O'Reilly and Reed, 2011) and how this relates to managerial practices and } \\
\text { identity. Empirical case study research from three hospital trusts in the UK } \\
\text { is presented. The findings highlight not only the many tensions associated } \\
\text { with this purported shift towards 'leaderism' in practice, but also how } \\
\text { interpretative flexibility associated with the concept of leadership has itself } \\
\text { an important bearing upon understanding attempts to bridge long-standing } \\
\text { managerial divides within healthcare. }\end{array}$ \\
\hline \hline
\end{tabular}

\section{SCHOLARONE \\ Manuscripts}




\title{
Leadership talk: from managerialism to leaderism in healthcare after the crash
}

\begin{abstract}
The economic downturn that began in 2008 led to massive cuts in spending targeted at managerial activities in the UK National Health Service (NHS). Although the appellation 'manager' once conferred status in the NHS (Learmonth, 2005) managers have borne the brunt of reform and the term itself is in danger of falling into disrepute. Drawing upon perspectives on leadership that emphasise its constitutive nature (Grint, 2005), we examine the growing alternative emergent culture of 'leaderism' in the NHS (O'Reilly \& Reed, 2011) and how this relates to managerial practices and identity. Empirical case study research from three hospital trusts in the UK is presented. The findings highlight not only the many tensions associated with this purported shift towards 'leaderism' in practice, but also how interpretative flexibility associated with the concept of leadership has itself an important bearing upon understanding attempts to bridge long-standing managerial divides within healthcare.
\end{abstract}

\section{Introduction}

The economic downturn following the credit crisis of 2008 has been distinctive in its effects on white collar workers especially those in the public sector (Gabriel et al., 2010). This is no less the case in the UK National Health Service (NHS), particularly for those in middle management positions. Management within the NHS has been subjected to a considerable amount of critical attention in recent years with middle managers having a particularly poor reputation in spite of their importance to large organisations (Brocklehurst et al 2009). As a 
result they are one of the publicly undisputed and less contentious targets of the 2010 UK Government reform which announced cuts to management costs of $45 \%$ (DH, 2010). In contrast, and mirroring a distinction long made elsewhere (Zaleznik, 1977), it is more effective leadership within the NHS that is seen as offering a potential solution to continuing organisational and managerial problems in the NHS (King's Fund, 2011).

The appellation 'manager' in the NHS once conferred status on its occupational owner having superseded the role of 'administrator' as the dominant category in public service organisations (Learmonth 2005). However, in the context of cuts targeted at management activity, calls for alternative ways of mobilising and delivering healthcare - primarily articulated as providing better 'leadership' (O'Reilly \& Reed, 2011) - have become louder and more strident. Consequently, not only is the term 'manager' in danger of falling into disrepute and disuse, it has also started to become - in the healthcare sector at least something of a residue or scapegoat category.

This paper examines the implications for management in healthcare, building upon the work of O'Reilly and Reed (2011) and others who critically examine the emergence of an alternative discourse of leaderism in healthcare (Blackler, 2006; Martin \& Learmonth, 2012; Tomlinson et al., 2013). It sets out to explore at the level of management practice how these changes in discourse are reflected in the ways in which managers understand and articulate their own management responsibilities and leadership actions. It does so by subjecting the notion of leadership as enacted in healthcare to critical examination, drawing upon the work of Grint (1997, 2005, 2010) and others (e.g. Denis et al., 2010; Ford, 2010; Tomlinson et al., 2013; Wallace \& Tomlinson, 2010) who highlight the constitutive and highly situated nature of leadership. Consequently, attention is directed towards understanding the discursive resources managers in healthcare draw upon to make sense of leadership in relation to their management practices and their professional identity as managers and how the instantiation

\section{http://mc.manuscriptcentral.com/leadership}


of leadership action in management practice thus relates (recursively) to wider discourses of managerialism and leaderism (O'Reilly \& Reed, 2011).

Empirically, the paper recognises that neither the roles performed by managers in healthcare, nor the organisational context within which they perform them, can be considered unitary. Indeed, a good deal of attention has long been directed towards the challenges associated with understanding change in healthcare, where management itself is highly differentiated and leadership distributed and where change initiatives cut across the interests of a multitude of clinical and managerial professional/occupational communities of practice (Dopson \& Mark, 2003; Buchanan et al., 2007; Currie, 1997; Fulop \& Mark, 2013). Consequently, the research reported here is concerned as much with surfacing any important underlying differences in role and context that help shape how managers make sense of their leadership role, as it is with pursuing a line of analysis that presumes any consistency and similarity in the ways in which leadership qua management is understood and enacted.

Such an approach then opens up the possibility of exploring the possibility of both integrative and disintegrative consequences of any differences in orientations to discourses of managerialism and leaderism. At one level, for example, the discourse of leaderism may provide a way of helping to unite previously distant 'thought worlds' such as those represented by clinical and managerial domains (cf. Dougherty, 1992). At another level, however, it may signify a tension and possible further distancing between the aspirations for change that it represents and the realities of the demands placed upon often over-burdened NHS managers. The highly individualistic and embodied notions of leadership it gives rise to may, in turn, creates further potential contradictions in attempts to develop a professional managerial cadre based upon a shared knowledge base and a coherent community of practice (Ford, 2010). 


\section{The changing context of management in the NHS}

'Over the past decade, layers of national and regional organisations have accumulated, resulting in excessive bureaucracy, inefficiency and duplication. The Government will therefore impose the largest reduction in administrative costs in NHS history. Over the next four years we will reduce the NHS's management costs by more than 45\%.' (DH 2010:43)

Ideas about the nature, purpose and practices of management have undergone significant shifts in the last couple of decades as organisations have restructured and de-layered and government policy toward the management of the NHS has reflected these changes following a similar, if somewhat delayed, trajectory. Organizational changes have had striking effects on management practice, professional values and service delivery in the NHS as a whole (Buchanan et al, 2007) and it is possible to track changes in management ideologies (associated with attempted shifts from bureaucratic organisational forms to more flexible forms of organisation) that map broadly on to generations of managers in the NHS. Each generation brings with it a particular organisational discourse (e.g. managerialism, leaderism) that stresses the importance of particular management activities (Ford \& Harding, 2007; Learmonth, 2005).

The original aim of introducing general managers to the NHS was to develop a more powerful group of managers who would act not simply as administrators but as 'strategic change agents' and challenge clinicians' dominance (Currie 1997:304). Their introduction was inevitably accompanied by the apparatus of managerial control, including performance indicators (targets), incentive payments and quasi-market conditions - representing, as 
Thomas and Davies (2005: 684) put it; 'the ascendancy of the managerial prerogative and the legitimacy of management'.

Learmonth (2005) suggested that the title 'manager', in superseding 'administrator', conferred status on its holder. It has been noted, however, that the term 'manager' has since gone the way of the term 'administrator', being increasingly used to refer to those in first line management and other lower ranking managerial positions. Hyde et al (2012) found that few NHS managers were willing to identify themselves as managers and, where they were, this was subordinated to a primary non-managerial identity construction: i.e. nurse-manager; or consultant with some managerial responsibilities. It was also noted that the derogation of management has coincided with a significant reduction of emphasis on management in NHS policy and increased attention being given instead to leaders - and clinical leaders in particular - as the future managers of health services. Indeed, following the introduction of general management in the NHS in the mid-1980s, managers have constantly been challenged by difficult organizational relationships - not least with doctors (Davies \& Harrison, 2009) - reflecting the different orientations and logics of action that continue to divide business and clinical managers (Hyde, 2010).

Subsequent, centrally driven initiatives have focused on the development of leadership, for example, the NHS Leadership Academy championed the idea of the manager as leader - with responsibilities for leading change and complying with rapid-fire structural and policy changes. Similarly, the 2008 Darzi review emphasised the role of doctors as leaders. Rather than bringing about changes, however, it can be argued that these centralised initiatives operate as a covert means of perpetuating elite domination (Tomlinson et al., 2013). Moreover, the view of empowered, proactive leaders is at odds with the experiences of senior managers who find themselves 'little more than conduits' for national policy (Blackler, 2006:5). 
The declining confidence in management is by no means limited to managers in the NHS, or in healthcare. As Khurana and Nohria (2008) note in calling for the professionalization of management, managers face a 'widespread institutional breakdown of trust and self-policing in business', in the wake of a decade which has seen repeated incidents of malfeasance and corrupt practices in prominent corporations. Consequently, the role of the manager has been subject to a large amount of negative assessment. More recently, such negative profiling has affected both the self-image of middle managers (Merali 2003, Clarke, Brown \& HopeHailey 2009) and their ability to make strategic contributions (Currie \& Procter 2005). Moreover, this view has gone largely unchallenged (for exceptions see Huy 2001, Hassard, McCann \& Morris 2009).

Accompanying this loss of trust is, according to many, a more widespread proletarianisation or degradation of management as a role in the $21^{\text {st }}$ century (Ford 2010; McDonald 2004). This has been tied to a conception of the manager as bureaucrat, with their fall from grace in recent years being connected with the demise of bureaucracy from its heyday in the second half of the $20^{\text {th }}$ century (Scarbrough \& Burrell, 1996; Brocklehurst et al., 2010). Thus Brocklehurst et al. (2010) trace the rhetorical devaluation of the concept of manager, as ambitious employees disparage the ubiquity of management roles (Grey, 1999), and aspire towards, or rename themselves as, 'consultants', 'directors', 'leaders', 'change agents' and the like.

However, it is clear that the management role is even more embattled within the NHS, as a number of commentators have observed (Currie, 1997; 2006; McCartney et al, 1993; Preston \& Loan-Clarke, 2000; Kings Fund, 2011). Challenges to the status of management in the NHS have been accentuated by a number of factors, many of these significantly influencing public perceptions of NHS management. In particular, significant political mileage has been 
made in recent years by parliamentarians of all parties from references to 'men in grey suits' or 'pen pushers' (Kings Fund, 2010).

In that context, it is perhaps not surprising then that the discourse of 'leaderism' has taken much more of a hold in policy and practitioner thinking about the management of healthcare (O'Reilly and Reed, 2011). Through its emphasis on individual agency and the supposed (visionary and strategic) transformative capabilities it encapsulates, it clearly appeals to policy-makers and practitioners concerned with improving the perceived image and impact of management, in bridging gaps between aspects of service delivery, and in over-coming (structural) barriers to reform (Ford \& Harding 2007). According to O'Reilly and Reed (2011) leaderism is an emergent discourse that is rising to challenge the still dominant (but fading) discourse of managerialism and still-powerful (but residual) notions of professionalism that infuse managerial work in healthcare:

'leaderism identifies and advocates a much more charismatic, pro-active and visionary conception of leadership as a generic cultural resource and process to be mobilized by and diffused through a multiplicity of stakeholder agents' (O'Reilly \& Reid, 2011: 1090).

Consequently, a shift in discourse towards leaderism represents an attempt to instil in managers a much more strategically- and action-oriented approach that relies for its success on generic management skills rather than specific management knowledge. Whereas difficulties in defining a clear and uncontested knowledge base associated with the attempted 'professionalisation' of management practice can leave management itself invested with very limited symbolic capital (cf. Reed \& Anthony, 1992), the idealisation (cf. Ford, 2010) associated with 'leadership' can, it appears to be presumed, potentially render managerial action much more visible, purposeful and impactful. At the same time, it is clear from any 
critical analysis of policy and practitioner initiatives that the flexibility afforded by the concept of leadership lends itself to a discourse of leaderism in healthcare management that tempers individual agency (Wallace \& Tomlinson, 2010). It does so by privileging the needs of the idealised service user/consumer, thereby creating a much more dispersed leadership agency that is intended to align managerial action much more closely with the logic and values of consumerism (O’Reilly \& Reed, 2011: 1090-1).

\section{Exploring leaderism, leadership and management in healthcare}

While central policy changes to healthcare may be encouraging an emergent discourse of leaderism they also indicate a great deal about the pressures facing NHS management. At the same time there remain a number of important questions about what this means for the shape and direction of changes in managerial work and how the expectation that managers increasingly assume the mantle of leadership translates into managerial practice and feeds into their evolving sense of managerial identity (cf Watson, 1994). So, for example, does the emphasis on leadership translate into different ways of thinking about, talking about and enacting management in healthcare? To what extent and in what ways do managers themselves engage with this discourse and how do they view the relationship between management and leadership in practice? Do different types of managers in the NHS who have historically engaged in quite different ways with managerialism (McNulty et al., 1994) respond in similar or different kinds of ways to the emergence of leaderism (e.g. Spurgeon et al., 2011)?

Understanding how the discourse of leaderism relates to conceptions of leadership in practice requires a critical perspective on leadership (and its relationship to management) that is not only open to the hotly contested nature of the concept, but also sensitive to how meanings 
and understandings of leadership are both constructed and highly situated (Alvesson \& Spicer, 2012; Denis et al., 2010; Grint, 2005; Wallace \& Tomlinson, 2010). Grint's (1997, 2005) work is particularly useful here as it highlights the constitutive nature of leadership as an alternative to mainstream perspectives, allowing an understanding of the ways in which leadership itself is socially constructed as well as how situations themselves are actively framed as requiring different forms of (leadership) action. Understanding what 'leaderism' means in the healthcare context then not only involves the critical examination of public pronouncements and policy initiatives, but also depends upon an in-depth analysis of the recursive relationship between those initiatives on the one hand and managerial understandings, practices and action on the other (Martin \& Learmonth, 2012). In other words, what discursive resources are managers themselves drawing upon to make sense of their own situation? How does this relate to expectations of leader behaviour and how does this tie in with their experiences and their professional and managerial identity?

An emphasis on the situated nature of leadership also underscores the importance of context and the shaping of that context - in influencing any unfolding discourse of leaderism across the sector (Denis et al., 2010; Ford, 2010; Wallace \& Tomlinson, 2010). Work on management in the healthcare sector has long emphasised the importance of understanding the complex institutional context and intricate organisational/professional relationships affecting any attempt to introduce organisational or management change (McNulty \& Ferlie, 2002). Particularly prominent and difficult in any change situation are the multitude of professional interests and power bases that may need to be appreciated and through which any change initiative may need to be navigated (Dopson \& Mark, 2003; McDonald, 2014a \& b). However, attention has increasingly been directed towards understanding the more intricate and active ways in which the context itself impacts upon processes of change given 
the complex processes, fuzzy management inter-relationships and blurred organisational boundaries found in healthcare organisations (Dopson et al, 2008; Fulop \& Mark, 2013).

Clearly, unpacking the emergence of the discourse of leaderism is an important way of starting to highlight how the shaping of management practices at a local level are inextricably linked to wider processes of institutional change (O'Reilly \& Reed, 2011). However, to help produce a more complete picture, it is important to take into account that management within healthcare is also highly variegated and differentiated (Currie, 1997). Any further examination of the discourse of leaderism in healthcare and how it is instantiated in management practice needs to contend with the highly distributed nature of management in healthcare (Buchanan et al., 2007; McDonald, 2014a). Not only does this mean that unitary conceptions of what leadership is intended to mean may themselves have been (and are being) shaped by the context in which they arise; it also suggests that they may have more or less traction with particular managerial communities within healthcare depending upon how well they mesh with existing preconceptions, orientations and practices. Moreover, what are the implications for the spread of a discourse of leaderism if one is dealing with a context that almost defies an understanding of leadership in any unitary, individually embodied way (Buchanan et al., 2007)?

The aim and contribution of this paper is to explore the discourse of leaderism in healthcare further by examining how management and leadership are understood and articulated by healthcare managers in practice and how they see the changing nature, activities and challenges of their role. Consequently, the emphasis is on understanding the (inter-)subjective constructions of leadership and management and the ways in which leadership and management are made sense of, and articulated, by managers in the light of their particular experiences, practices and context (Wallace \& Tomlinson, 2010). Given that there is enormous diversity in occupational and organisational circumstances across this very 
heterogeneous group, it is also important to try to capture a sense of some of the ways in which any variations in managerial practice, background and identity and organisational context feed into managers' changing conceptions of their role in healthcare management.

The empirical research reported next in this paper aims to capture some of that complexity by recognising three key aspects of the situation in healthcare that could be considered likely to have important effects on individual perceptions of management and leadership. First, that management in a healthcare setting consists of numerous groups with very diverse and distinctive professional and occupational orientations and knowledge bases (clinical, operational, functional, etc). Second, that such managers may (or they may not) develop and sustain their occupational/professional identity and knowledge base by virtue of their connections (or absence of connections) with a wide and diverse range of professional and occupational communities of practice. Some of these will be fairly distinct, institutionalised and influential (in medicine, accountancy, etc); others are likely to be more disparate, emergent and lacking influence (e.g. general managers or nurse-manager hybrid roles). Third, health service managers work in a variety of organisational settings (ranging from general hospitals to specialist units) that are likely to have implications in terms of the managerial work that they do and the resources they receive in performing that work and developing their managerial careers (e.g. training, development, IT support, etc).

\section{Research methods and data analysis}

The research on which this paper is based is taken from an NIHR (National Institute of Health Research) study in the UK [reference to be added]. The study set out to explore the perspectives of three 'clusters' of managerial groups - medical, general and functional specialists, within three NHS trusts in the same region of the UK. The research examined the 
developmental pathways of individual managers, focusing on their different approaches to learning and sharing knowledge, their networking activities, their perceptions of membership of managerial communities and/or professional groups and the ways and means by which organisations enabled or inhibited knowledge sharing, professional development and learning.

The trusts that participated in the study were selected to represent diverse activities (one general hospital (Acute), one trust providing mental health and community services (Care), and one hospital providing specialist (tertiary) care (Specialist). Within each trust/hospital, managers were selected on the basis of a framework (see Figure 1 below) that differentiated across a broad continuum between three broad clusters of managers - Clinical, General (operational) and Functional. Within each cluster, managers were purposively sampled to represent a range of operational and functional areas and selected for interview and observation if they had mid- to senior-level responsibilities. Apart from clinical staff who were employed on clinical grades, this corresponded mainly to people working at Grade 8 or 9 of the national pay scale (known as Agenda for Change) in the UK.

Figure 1: Management Supply Model

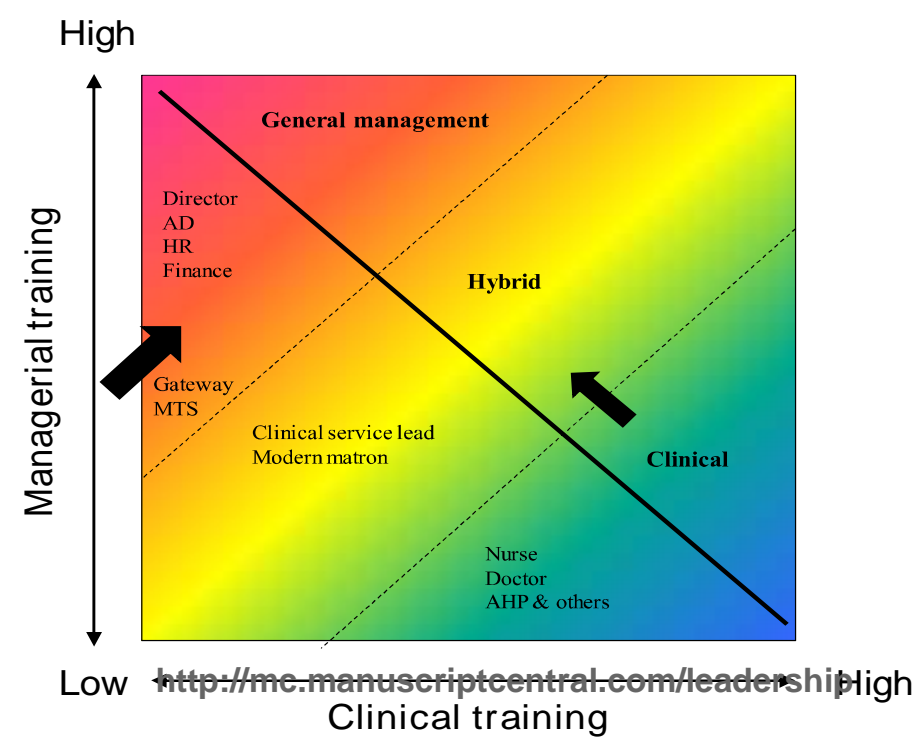


Semi-structured interviews, each conducted by at least two members of the research team, combined with observation of formal and informal events and meetings (from management meetings to training events) constituted the main methods of data collection. The focus of interviews was on managers' experiences of work, their perceptions of management and leadership and their knowledge networks. In total, 68 respondents were interviewed and 54 hours of observations were recorded. Repeat interviews conducted at each trust meant that a total of 85 interviews were conducted (see Table 1 below for a summary and breakdown by trust and by management cohort). In addition, the early, exploratory stage of the research had involved 13 interviews with key informants from across the sector, as well as preparatory meetings at each trust. Observational data were used to help ground the analysis of management and leadership in practice and also helped to provide a cross-check on accounts of particular management processes (e.g. training and decision-making in committees).

Table 1: Sample of interviewees by management group and by trust

\begin{tabular}{|l|l|l|l|l|l|}
\hline & $\begin{array}{l}\text { Clinical } \\
\text { Managers }\end{array}$ & $\begin{array}{l}\text { Functional } \\
\text { Managers }\end{array}$ & $\begin{array}{l}\text { General } \\
\text { Managers }\end{array}$ & $\begin{array}{l}\text { Total } \\
\text { Participants }\end{array}$ & $\begin{array}{l}\text { Total } \\
\text { Interviews }\end{array}$ \\
\hline Acute Trust & 5 & 7 & 8 & 20 & 22 \\
\hline Care Trust & 7 & 6 & 12 & 25 & 33 \\
\hline Specialist Trust & 6 & 8 & 9 & 23 & 30 \\
\hline Total & 18 & 21 & 29 & 68 & 85 \\
\hline
\end{tabular}

All interviews were recorded and transcribed and field notes from direct observations (of management meetings and training events) were also collected. Data were coded and analysed using NVivo software. Interview transcripts were initially coded independently by two members of the research team using open coding techniques (Strauss \& Corbin, 1990). 
Codes were then compared and discussed with a third member of the team to establish a common lexicon for interpretation and analysis. Most of the analysis that follows draws directly upon the interview data, although this is supplemented where appropriate with findings from the observations.

\section{Findings}

Management is around how you manage the day-to-day operations, the leadership is how you take your team forward and the direction that you want them to go in and how you want your service to develop (Hugh, Acute, General)

\section{Management and leadership?}

What was quite apparent across the data was the clear and consistent distinction that was drawn in almost all of the interviews between management and leadership. Typically, the former was said to relate closely to operational skills, whereas the latter was related to broader, more strategic and visionary change management aspects. For example:

I think leadership's more strategic, it's more about vision; having a vision of what's to come and where you want to go and taking people with you. I very much see management more as a day-to-day, more of an operational type concept really. Whereas leadership, I see that as being more strategic and it's making change and delivering change and driving things through people. (Stewart, Acute, General)

Perhaps not surprisingly, this dualism mirrors well established differences identified between management and leadership (e.g. Zaleznik, 1977) and/or forms of leadership that could be described as transactional and transformational (Bass, 1990). Indeed, in attempting to capture and summarise the coded interview responses across the entire sample of managers, Table 2 
1

2

below shows how - almost without exception - management was seen as much more concerned with the nitty-gritty of everyday activity, whereas leadership was associated with rising above the mundane to inspire and have impact.

Table 2. Contrasting portrayals of management and leadership

\begin{tabular}{|l|l|}
\hline Management & Leadership \\
\hline Nuts and bolts & Visionary \\
\hline Following policies, procedures, processes & Make decisions \\
\hline Day to day & Long term \\
\hline Can read it in a book & Can't be taught \\
\hline $\begin{array}{l}\text { Improved through (standard) training and } \\
\text { development experiences }\end{array}$ & $\begin{array}{l}\text { Natural born, charismatic } \\
\text { enhanced through self-awareness training }\end{array}$ \\
\hline Sat behind a desk & Being dynamic \\
\hline Getting people to do their jobs & $\begin{array}{l}\text { Helping people see why they do what they } \\
\text { do }\end{array}$ \\
\hline Very specific skill set & Influencing/inspiring people \\
\hline Safe services from standardisation & Improve services by taking risks \\
\hline Focus on task & Focus on strategy \\
\hline Bureaucratic & Heroic \\
\hline Enacted practices & Dynamic \\
\hline Embodied qualities \\
\hline .
\end{tabular}


Management skills were also considered to be much more acquired through experience, training and practice, whereas leadership skills were seen as natural qualities with which individuals were personally endowed. For example:

I think managerial stuff, it's something that you can probably be trained and taught. I think that leadership things are something that you maybe either have or you don't have, and it's more difficult to teach people those kinds of things. (Elena, Care, General)

It was notable that many of the characteristics of management undoubtedly fulfil important functions in healthcare - for example paying attention to detail, following policies and procedures exactly and having highly specialised skills - yet it was clear too that there was a preference for leadership over management. Descriptions of leadership qualities invested individuals with seemingly heroic qualities and the ability to envision the future in ways that resonated with conceptions of leadership based around the metaphor of messiah (Western, 2008; Ford 2010; Grint, 2010). In contrast, management was portrayed as a dull, procedural function that involved following policies and procedures, focusing on tasks and getting the day to day 'nuts and bolts' of the job done well. For instance:

For me ... a leader is someone that is very visionary, innovative ... they're the people who can sit in a room and come up with something that nobody else can think about. You take people with you, you get people on board, you take them with you but you're not frightened of making that decision that needs to be made that's not the general consensus or the popular decision ... As a manager ... you just tell people what to do. Don't really go very far ... I guess managers just manage don't they? (Ellen, Specialist, Functional) 
There were, of course, exceptions to this depiction of leadership and management and one or two (general) managers at the care trust in particular did emphasise instead the importance of managers showing leadership by 'getting their hands dirty' - which perhaps reflects the very different nature of patient care at this trust. But, even here, there was a strong connection with a more inspiring and less distanced take on leadership that was fairly consistent with the generally espoused duality. For example:

I think the way you prove you're a leader in this role is by leading by example, by sorting things out that are quite difficult to sort out, by being on the ward, by being present, by mucking in, by showing that you're able to (Luke, Care, General)

This duality emerged in almost every interview (with aphoristic consequences spelt out in ways such as: 'Management without leadership is weak' and 'we're over-managed and under-led'). However, it was also clear that there was a great deal of indeterminacy and elusiveness in those almost sacred properties attributed to leadership (cf Bresnen, 1995). This was not only due to its personal embodiment in the attributes of individuals, but also in the way that making sense of it tended to break down in practice as it became difficult to disentangle from the depiction of day to day operational concerns. It was also reflective too of how the aspirations of exercising leadership confronted the realities of the pressures and demands of everyday managerial work.

I take my responsibility as a leader really seriously, but I do think the organisation pay lip service to leadership. I think they'd be quite keen to demonstrate to CQC or whatever that we've had so many people go through the senior management academy ... I was fortunate to go on ... a really good [named] leadership programme ... and it was really empowering at the time ... I'd literally only been away one day a week for 
ten weeks and come back and I've got another service to manage. It's like okay ... now where do I fit it into my week? (Gloria, Acute, General)

While the above quote highlights the abstraction of leadership training from daily experience, what was interesting to observe in the local leadership training programme for managers at the care trust, for instance, was the value placed by instructors and participants alike in having leadership training that aligned extremely closely with practice. Here, the issue was the need to avoid being abstract in order to enhance the appeal and engaging qualities of the course and to enable its learning to be applied directly to practice. The result, however, was the distillation of leadership thinking into practical management steps to be taken in dealing with specific cases and scenarios - often in ways that invoked reflection on participants' organising or inter-personal skills.

A similar emphasis on the displacement of energy into dealing with operational matters despite the intention of creating space to think more strategically, can also be seen in the following example:

[Our] chief exec [is] very keen on [saying] we're going to get together on this Wednesday afternoon for a strategic leadership group or with the clinical directors, and this is going to be our thinking time about where we're headed. But then by the time everybody's put their little bit on the agenda, it's just become another committee ... you get an agenda that's four hours, while we just say you need to know this, you need to know that. And the clinical teams are just absolutely bored to death with it. They want to be in there, discussing the future, rather than, you know, what's changing in finance this month or whatever. (Greg, Acute, General)

Observational data from management meetings tended to confirm that, stylistic differences apart, there was a good deal of similarity across the three trusts in the ways they were driven 
by (largely external) reporting requirements and an agenda that left little room for these more strategic level discussions.

In practice too, there were some important differences in the context of managerial action across the cases which made the exercise of management/leadership highly situated and which therefore was still likely to thwart attempts to translate common values and visions associated with leadership into action. A particular difference that emerged here was in the emphasis placed upon the more abstract, strategic nature of leadership in the specialist trust case (where clinical/scientific expertise was a core competence and highly valued) and the earlier noted emphasis on 'leading by example' and becoming more personally involved in the care trust case (where clinical and managerial orientations were often embodied in the nursing backgrounds of operational managers).

I think a lot of leadership is about getting your hands dirty with everybody else and not sitting there and going, well, you all do it ... So it is a kind of a lead by example, rather than just think up a fancy strategy and waiting for everybody who has got a day job to have to do it (Kerry, Care, General)

Consequently, the simple dualities - leadership as a natural quality whereas management is an acquired skill - were clearly felt and articulated but not always borne out when it came to detailed explanations of how managers went about their work in their specific context. The discourse of leadership rapidly dissipated in practice, as local concerns and requirements came to the fore and conceptions of leadership 'defaulted' to those associated with management activity and managerial identity (Carroll and Levy, 2008).

Leaderism and the clinical-managerial divide 
As expected, there was a good deal of opinion forthcoming on the problems and challenges faced in bridging the clinical-managerial divide in the NHS, not least due to the negative view that each side could have of the other:

A lot of managers have very poor views of clinicians, they think they're a lazy bunch ... in the same way as clinicians describe managers as, you know, paper clip counters. It's equally derogatory in both ways. (Brian, Acute, Clinical)

There was also a widespread perception that clinicians or clinician-managers were most resistant to management/leadership development - certainly among senior management and amongst those involved in delivering such courses. For example:

I've normally found people who are clinicians and managers don't seem to get the balance right because they'll always throw back to the clinician part and they won't be able to think as a manager. There's very, very few clinical managers that I've come across that have been successful, like clinical directors, because they don't have training. (Joanna, Specialist, General)

However, what was interesting to note was the degree of receptivity to the idea that clinical and managerial responsibilities could go hand in hand. This was particularly the case at the care trust where the clinical background of operational managers both created a dual sense of identity and purpose but also created challenges and opportunities for the managers involved in reconciling the tensions.

I've been in a number of meetings with consultants who've said well, we can't do that, clinically that wouldn't be viable, but I've done it or other people have done it. So it's about, I think, that's harder than me, say, if I go into a room as a business manager they just see the label. But I've lived and breathed their culture so I understand it (Glen, Care, Clinical) 
However, there were also examples of subversion of the leadership discourse from staff more clearly associated with higher status roles, namely, doctors. This doctor drew upon the negative connotations of 'manager' to positively evaluate himself:

I quite like to describe myself as a medical manager, because I quite like to not pretend I'm one of the clinicians who only does management resentfully, I, kind of, like to say, no, you know what? I'm one of the baddies. I'm one on the other side, (Brian, Acute, Clinical)

By contrast, it was interesting to note the importance attached to the role of the clinical manager as leader, as it appeared to signify a way in which the tensions between the operational requirements of managers and the inspirational/visionary aspirations of leaders could be reconciled:

I think it's about being seen as a leader, as a clinician that people are in awe of. I don't know how you get that, but it's about being constant and reliable and credible within your organisation, credible within the field that you're in. I think it's having the skills to get people to do what you need them to do, because as a manager you can just say I want you to do that and people will think I'm not doing that. (Thea, Care, Clinical)

This strong emphasis on the importance of clinical credibility as the basis of influence, expressed through the vehicle of leadership rather than management, was also clearly evident in the following example:

Most of the clinicians are not in the clinical director roles, or the divisional director roles ... They want to lead the service, they want to shape the service, they want to set the strategy for their services, they don't want to deal with the operational day to day 
... (They think) I didn't come into medicine to be a manager. They want to be a leader and they want the kudos! They don't deal with money, they don't deal with targets but, you know! Strategy, yeah, they like strategy. (Annette, Specialist, General)

Observations such as this suggests not only that leadership has greater traction amongst some managerial groups than others, but also that its discursive power may even help transcend entrenched status differentials between some, if not all, professional/occupational groups. Ironically, perhaps, if there is a way of bridging the clinical managerial divide in a way that reinforces the credibility of each party in the eyes of the other, then any persistent indeterminacy in the concept of leadership may potentially play an important part (Martin \& Learmonth, 2012; McDonald, 2014a).

\section{Discussion}

The study took place as NHS management cuts following the financial crisis were starting to bite. All the managers involved worked for organisations that were reducing managerial costs through regrading and redundancies. The findings above highlight a number of features about managers' perceptions and constructions of leadership and how these relate to their own work situation and their managerial responsibilities and practices. While there are a number of important similarities that emerged across managerial groups and across different trusts in how leadership and management processes were understood and articulated, there were also some differences and subtle nuances that emerged and that will be drawn out in the following discussion.

The first and most striking observation about how managers talked about and understood leadership in the context of healthcare was in the very clear and stark distinction drawn 
between leadership and management that mirrored a very well established discourse that distinguishes between more transactional (managerial) and more transformational (leadership) approaches (Zaleznik, 1977; Bass, 1990). At one level this is not very surprising perhaps - practicing managers have long been exposed to this dualism in thinking about the two concepts and this may be regularly reinforced through the discursive resources made available to them through the leadership training and development they received (Ford \& Harding, 2010; Tomlinson et al., 2013). Moreover, there are clearly strong elements of this distinction that underpin the shift from managerialism to leaderism (O'Reilly \& Reed, 2011). Indeed, it would be surprising if managers did not draw such a distinction given the prevailing discourse surrounding change in the healthcare sector (Martin \& Learmonth, 2012).

At the same time, however, what was equally striking was the clarity and firmness of the distinction and the very real sense that can be got from the quotes of what associations managers were making when they talked about leadership in their particular healthcare setting and how they felt it connected or (more accurately) disconnected with their managerial work (Ford, 2010). It was clear that the distinction between leadership and management reflected differences between what were considered, respectively, 'important' and 'humdrum' aspects of managerial work (Martin \& Learmonth, 2012). The leadership aspects of the role were clearly idealised and valued over and above the more mundane, 'technical' aspects of managerial work (particular attention here was placed not only on operational requirements, but also on HRM and financial management aspects).

Moreover, there was a clear recognition too across the cases and cohorts of managers of the challenges they faced in being able to create the space and time to develop their leadership capabilities and to enact what they saw as leadership - through, for example, thinking strategically and championing more innovative practices. Often, the best that could be

\section{http://mc.manuscriptcentral.com/leadership}


achieved by busy managers facing demands and pressure on all fronts was to aspire to inspire as best they could, using interpersonal skills that were considered, above all else and across the sample (and particularly in the care trust), of primary importance amongst their management skill sets. This emphasis on relying upon managers' interpersonal skills (as opposed to exercising leadership) was a subtle differentiation easily made by many of those interviewed (and observed in training) and showed how easy it was for managers to distil their ideal of leadership into the practical skill sets associated with what they saw as more routine day-to-day management activity. Such a translation also interestingly dovetails with the presumption - commonly associated with transformational/charismatic views of leadership - that management skills such as these can be learned (usually on the job) but that leaders are born and not made.

While such a clear normative distinction between management and leadership might at first sight appear to confirm a shift towards a discourse of leaderism (O'Reilly \& Reed, 2011), it also suggests a more nuanced interpretation in which the conditions facing those managers were being construed as creating much more of a breach between their leadership aspirations and the more pressing demands of their managerial roles and responsibilities (Tomlinson et al., 2013). The denigration of management in healthcare referred to earlier was clearly symbolised by a discounting of the more mundane aspects of management; but the idealisation of leadership was explicitly contrasted with what was seen as achievable - not only given the emphasis on personal characteristics, but also in the light of everyday demands that effectively 'crowded out' leadership activity. In other words, managers who were feeling increasingly alienated from their managerial identity were finding it difficult to envisage adopting fully an alternative identity based on acting as 'leaders' (Carroll and Levy, 2008; Ford, 2010). Leadership was reified instead and often appeared beyond the grasp of busy, preoccupied managers. 
While such an interpretation is consistent with a more critical view of the shift towards leaderism in healthcare (since it emphasises the constraints on action once we move beyond very senior management), it does however raise questions about the tenacity of a discourse that depends for its appeal upon enrolling middle managers into the practice of leadership. The managers we studied occupied relatively senior positions in their healthcare organisations, but still did not feel sufficiently empowered to act as leaders in what they saw as desirable ways (Blackler, 2006). Framing situations as those involving or needing to involve leadership (cf Grint, 2010) more often meant abstracting from, or unfavourably contrasting with, operational scenarios than it did instantiating leadership in day-to-day management activity. As already noted, 'getting your hands dirty' was the exception to the rule that leadership dynamics were more commonly associated with creating and inspiring a vision. Where, as in this case, managers related leadership and leading much more closely to the specific managerial challenges they faced in their own particular context, they tended to frame leadership in a much more pragmatic way, discounting the strategic and visionary aspects in the search for something more practical and useful to them (Denis et al., 2010; Wallace \& Tomlinson, 2010). In doing so, they were inevitably falling back on a more problem-focused and action-oriented view of leadership that was perhaps more closely associated with management responsibilities and the exercise of management skills.

Consequently, there was an obvious mismatch between the ideal of leadership and its manifestations in practice. When one drills down a little further, it becomes clear moreover that the variability in context and managerial practice - in the managerial work undertaken within and between the three managerial cohorts and across the three trusts - ensured that any practical understanding of exercising leadership was going to be highly situated in local conditions and management practices (cf. Grint, 1997, 2005). At the same time, the particular discursive resources used by managers to make sense of leadership suggest that these were 
likely to attenuate the relationship further insofar as they simply reinforced managers' views of a clear distinction between what they considered idealised notions of leadership and the reality of managerial work they faced (Ford, 2010; Martin \& Learmonth, 2012). Where training and development occurred that drew upon and reinforced such clear-cut distinctions, it might in some ways simply add to the problem rather than enhance leadership capabilities either by reinforcing perceptions of a gap between leadership in theory and in practice, or by catering too much to the need to translate leadership constructs into practical management situations. In other words, it is difficult to see in this situation a normalisation of behaviour based upon received and accepted notions of leadership in action and there is even the distinct possibility that managers were effectively being conditioned through operational demands and even, by default, their training to accept and internalise limits to the possibilities of their leadership (Blackler, 2006; Tomlinson et al., 2013).

In stressing an obvious gap between the discourse of leadership and the reality facing managers in practice, the discussion so far has drawn upon the indeterminacy and interpretative flexibility long associated with the concept of leadership (Alvesson and Spicer, 2012; Bresnen, 1995; Grint, 1997; Martin \& Learmonth, 2012). However, this interpretative flexibility works both ways. This has already been shown through the tendency that managers had to view their fragmented experiences through the prism of more abstract notions of leadership identified earlier. At the same time, however, there were ways in which the discourse of leadership and the indeterminacies it highlights had consequences for the prospects of bridging between diverse professional/occupational domains, thus influencing relations between managerial and non-managerial groups (McDonald, 2014a).

Particular attention in the data was directed towards examining the different ways that leadership was encountered and understood across the clinical-managerial divide. In a context noted for distributed leadership and the importance of inclusivity, collective action and 
collaboration (Buchanan et al, 2007), one implication is that the concept of 'leadership' provides much more of a common lexicon and shared set of meanings than does 'management' to help bridge the divide between those communities of practice (McDonald, 2014a). Clinicians (mainly doctors) were clearly still very ambivalent about their managerial responsibilities not least because of their effect on status and autonomy (McDonald, 2014b). But, for those clinician managers who were open to it, leadership was much more synonymous with what they aspired to as managers (Ford, 2010). As has already been noted elsewhere, they are far more likely to engage with a leadership discourse than to consider themselves as managers per se (Hyde et al., 2012; Spurgeon et al, 2011). Whether or not this has practical consequences for communications between those two domains of practice, it does suggest perhaps more of a shared sense of identity based on a common recourse to a shared discourse.

However, it also raises important questions about the extent to which any purported shift to 'leaderism' in healthcare has consequences for the changing relative influence of, and relationships between, these different professional/occupational groups. If clinicians are more readily able to deploy the discourse of leadership in favour of clinical interests while managers are still trapped in their managerial preoccupations, then there are implications for the extent to which a shift towards a discourse of leaderism actively (if not necessarily intentionally) reinforces the dominance of one set of interests over the other and so makes it more difficult to overcome any existing power imbalance that are associated with the clinicalmanagerial divide (Martin \& Learmonth, 2012). The results do, of course, emphasis the differences that are likely to occur in this respect at different locales and across different types of healthcare institution (where common recourse to leadership based on clinical credibility may be easier if embodied in the knowledge base of individuals (as in care), rather than structurally separated, as in the other two cases). However, that simply reinforces the 
importance of understanding further how leadership is situated in practice and plays out in ways that recursively link local situated action and wider institutional discourse (Denis et al., 2010; Wallace \& Tomlinson, 2010).

\section{Conclusions}

This analysis of extant discourses among managers in the NHS during the financial crisis has indicated the tensions associated with a shift towards 'leaderism'. The overall implication of the paper is that there is some value in drilling down further into situated understandings of management and leadership in the context of changes in the NHS. One implication is that such an exercise highlights stark similarities but also subtle and important differences in the ways in which leadership is understood and related to management practices and managerial identity that affect flows of management knowledge and learning related to leadership and management activity within and between healthcare organisations. Consequently, understanding the nature and effects of the discourse of leaderism in healthcare requires a much more nuanced view of the enactment of leadership in practice and its meaning and significance for the various professional/occupational groups within management in the organisational/operational contexts in which they are embedded. Another implication is that, while the concept of 'leader' might have some integrative benefit in being more palatable to clinicians and other key stakeholders, it only adds further to the derogation of management in that setting while presenting an elusive ideal that is often at odds with the pressures of managerial work that they face. In the context of the changes that have occurred to healthcare in the years following the financial crash, the emerging discourse of leaderism consequently represents not only a means of ratcheting up expectations of an arguably alreadyoverburdened healthcare managerial workforce, it also demonstrates the continued power that 
the concept of leadership has, through the interpretive flexibility with which it is imbued, simultaneously to present an attractive vision of change while rendering more opaque the link between associated performance expectations and the ability of managers to achieve them.

\section{Acknowledgements}

[To be added]

\section{References}

Alvesson, M., \& Spicer, A. (2012) 'Critical leadership studies: the case for critical performativity', Human Relations, 65(3): 367-90.

Bass, B. M. (1990) 'From transactional to transformational leadership: learning to share the vision', Organisational Dynamics, 18: 19-31.

Blackler, F. (2006) 'Chief executives and the modernization of the English National Health Service', Leadership, 2(1): 5-30.

Bresnen, M. J. (1995) 'All things to all people? Perceptions, attributions and constructions of leadership', Leadership Quarterly, 6 (4): 495-513.

Brocklehurst, M. Grey, C. \& Sturdy, A. (2009) 'Management: the work that dare not speak its name', Management Learning, 41(1): 7-19.

Buchanan, D., Addicott, R., Fitzgerald, L., Ferlie, E. \& Baeza, J. (2007) 'Nobody in charge: distributed change agency in healthcare', Human Relations, 60(7): 1065-1090. 
Carroll, B. and Levy, L. (2008) 'Defaulting to management: leadership defined by what it is not', Organisation, 15(1), 75-96.

Clarke, C.A. Brown. A. \& Hope Hailey, V. (2009) 'Working identities? Antagonistic discursive resources and managerial identity', Human Relations, 62(3): 323-352.

Currie, G. (1997). 'Contested Terrain: The incomplete closure of managerialism in the health service', Health Manpower Management, 23(4): 123-132.

Currie, G. \& Proctor, S. (2005) 'The antecedents of middle managers' strategic contribution: the case of a professional bureaucracy', Journal of Management Studies, 42(7): 1325-1356.

Davies, H.T.O. \& Harrison, S. (2003) 'Trends in doctor manager relationships', British Medical Journal, 326: 646-649.

Denis, J.L. Langley, A. \& Rouleau, L. (2010) 'The practice of leadership in the messy world of organizations', Leadership, 6(1): 67-88.

DH (2010) Equity and Excellence: Liberating the NHS London: Department of Health.

Dopson, S., Fitzgerald, L. \& Ferlie, E. (2008) 'Understanding change and innovation in healthcare settings: reconceptualising the active role of context', Journal of Change Management, 8(3-4): 213-31.

Dopson, S. \& Mark, A. (2003) (eds) Leading healthcare organisations. Basingstoke: Palgrave Macmillan.

Dougherty, D. (1992) 'Interpretative barriers to successful product innovation in large firms', Organization Science, 3(2): 179-202.

Ford, J. (2010) 'Studying leadership critically: A psychosocial lens on leadership identities', Leadership, (6)1: 47-65. 
Ford, J. \& Harding, N. (2007) 'Move over management: we are all leaders now' Management Learning, 38(5): 475-498.

Fulop, L. \& Mark, A. (2013) 'Leading in healthcare - foregrounding context', Leadership, 9(2): 151-61.

Gabriel, Y. Gray, D.E. \& Goregaokar, H. (2010) 'Temporary derailment or end of the line? Managers coping with unemployment at 50', Organization Studies, 31(12): 1687-1712.

Grey, C. (1999), "’We Are All Managers Now"; "We Always Were": On the Development and Demise of Management', Journal of Management Studies, 36: 561-585.

Grint, K. (1997) (eds) Leadership: classical, contemporary and critical approaches. Oxford: Oxford University Press.

Grint, K. (2005) 'Problems, problems, problems: the social construction of "leadership"', Human Relations, 58(11): 1467-94.

Grint, K. (2010) 'The sacred in leadership: separation, sacrifice and silence', Organization Studies, 31(1): 89-107.

Hassard, J., McCann, L., \& Morris, J., (2009) Managing in the Modern Corporation: The Intensification of Managerial Work in USA, UK and Japan, Cambridge: Cambridge University Press.

Huy, Q.N., (2001) ‘In Praise of Middle Managers', Harvard Business Review, 79: 72-9.

Hyde, P. Granter, E. McCann, L. \& Hassard, J. (2012) 'The lost health service tribe: In search of middle managers'. In Dickenson, H. Mannion, R. The Reform of Health Care: Shaping, adapting and resisting policy developments Ch1. P7-20. 
Hyde, P (2010) 'Changing relationships between health service managers: confrontation, collusion and collaboration' In Braithwaite, J. Hyde, P. Pope, C. (Eds) Culture and climate in health care organizations Basingstoke: Palgrave MacMillan Ch8, 97-108.

Khurana, R. \& N. Nohria (2008). 'It's Time to Make Management a True Profession', Harvard Business Review, 86(10): 70-77.

Kings Fund (2011). The Future of Leadership and Management in the NHS: No More Heroes. London, The Kings Fund.

Learmonth, M. (2005) 'Doing things with words: the case of "management" and “administration", Public Administration, 83(3): 617-637.

Martin, G. \& Learmonth, M. (2012) 'A critical account of the rise and spread of "leadership": the case of UK healthcare', Social Science and Medicine, 74: 281-288.

McDonald, R. (2014a) 'Leadership and leadership development in healthcare settings - a simplistic solution to complex problems?' International Journal of Health Policy and Management, 3(5): 227-229.

McDonald, R. (2014b) "'Bourdieu", medical elites and "social class": a qualitative study of “desert island" doctors', Sociology of Health and Illness, 36(6): 902-916.

McDonald, R. (2004) 'Individual identity and organisational control: empowerment and modernisation in a primary care trust', Sociology of Health and Illness, 26(7): 925-950.

McNulty, T. \& Ferlie, E. (2002) Reengineering healthcare: the complexities of organisational transformation. Oxford: Oxford University Press.

Merali, F. (2003) 'NHS managers' views of their culture and public image: The implications for NHS reforms', The International Journal of Public Sector Management, 16(7): 549-563. 
O'Reilly, D. \& Reed, M. (2011) 'The grit in the oyster: professionalism, managerialism and leaderism as discourses of UK public services modernisation', Organization Studies, 32(8): 1079-1101.

Reed, M. I. \& Anthony, P. D. (1992) 'Professionalising management and managing professionalization: British management in the 1980s', Journal of Management Studies, 29(5): 591-614.

Scarborough, H. \& Burrell, G. (1996) 'The Axeman Cometh: The Changing Roles and Knowledges of Middle Managers'. In Clegg, S and Palmer, G (eds) The Politics of Management Knowledge. London: Sage.

Spurgeon, P., Clark, J. \& Ham, C. (2011) Medical leadership: from the dark side to centre stage. London: Radcliffe Publishing.

Strauss, A. \& Corbin, J. (1990). Basics of Qualitative Research: Grounded theory procedures and techniques. Newbury Park, CA: Sage.

Thomas, R. \& Davies, A. (2005). 'Theorizing the Micro-politics of Resistance: New public management and managerial identities in the UK public services', Organization Studies, 26(5): $683-706$.

Tomlinson, M. O’Reilly, D. \& Wallace, M. (2013) 'Developing leaders as symbolic violence: reproducing public service leadership through the (misrecognised) development of leaders' capitals', Management Learning, 44(1): 81-97.

Wallace, M. \& Tomlinson, M. (2010) 'Contextualizing leader dynamics: how public service leaders endeavour to build influence', Leadership, 6(1): 21-45. 
Watson, T. (1994) In search of management: culture, chaos and control in managerial work London: International Thompson Business Press.

Western, S. (2008) Leadership: a critical text. London: Sage.

Zaleznik, A. (1977) 'Managers and leaders: are they different?', Harvard Business Review, $55(3), 67-78$

http://mc.manuscriptcentral.com/leadership 